\title{
The Impact of CSR and Semi-TDPD on Price-Based Revenue Sharing Contract
}

\begin{abstract}
M. Shafiei ${ }^{1, *}$ and M. Modarres ${ }^{2}$
We develop a new coordination contract of manufacturer-retailer in a distribution system. A revenue sharing contract based on retail price is modelled, which is more practical to handle channel conflict. We also integrate two concepts of CSR (Corporate Sociality Responsible) and Semi-TDPD (Semi Third Degree Price Discrimination) into our model. Semi-TDPD strategy makes it possible to exploit the opportunity of customer behavior, by adopting a price discrimination strategy. According to this strategy, some customers who cannot or are not willing to pay the posted price, are allowed to purchase at lower prices through bargaining. To illustrate the proposed approach, we present some numerical examples. Through these examples, we investigate the impact of CSR and Semi-TDPD on decisions and also the good performance of this coordination.
\end{abstract}

Keywords: Revenue sharing, Distribution channel, Pricing, CSR, Semi-TDPD, Stackelberg game model

Manuscript was received on 20/02/2017, revised on 10/12/2017 and accepted for publication on 04/01/2018.

\section{Introduction}

A coordination contract improves supply chain performance by reducing the possible conflicts which may arise. Furthermore, self-interested objectives of channel members leads to suboptimal solutions. Although centralized systems provide higher profits as compared to decentralized decision systems, it hardly can be practical for many real world cases. Therefore, to improve the performance of decentralized systems an appropriate coordination contract need to be developed. Revenue sharing is a popular mechanism of coordination strategy. In recent years, some new concepts such as CSR (Corporate Sociality Responsible), TDPD (Third Degree Price Discrimination) have enriched supply chains in practice, although they have increased the complexity of the coordination modeling. Here, a new type of revenue sharing coordination is developed that provides the possibility of bargaining option and considers CSR and Semi-TDPD concepts.

Broadly speaking, CSR can be defined as a doctrine that promotes an expanded social stewardship by companies and business organizations. CSR (Corporate Sociality Responsible) suggests that corporations embrace responsibilities toward a broader group of stakeholders (customers, employees and the community at large) in addition to their customary financial obligations to stakeholder [1]. Many brands face intense pressure for socially responsible supply chain management [2], while a

* Corresponding author

1 Department of Industrial Engineering, Sharif University of Technology, Tehran, Iran, Email: Shafiei_m@ie.sharif.edu.

2 Department of Industrial Engineering, Sharif University of Technology, Tehran, Iran, Email: Modarres@sharif.edu 
commonly noted response to this pressure is to introduce a code of conduct to be socially responsible [3].

Although it is widely observed that practicing CSR is mainly the responsibility of manufacturer [2], all members of the channel may also involve in it. Thus, it is assumed that both the manufacturer and the retailer invest in CSR and align their goals with channel performance. It is obvious that when a firm practices CSR, its stakeholder's welfare increase, and customers pay a higher price for the product. From a recent survey, $74 \%$ of the top 100 U.S. companies (from the point of revenue) have published CSR reports in 2008. This has increased from 37\% in 2005. Globally, 80\% of the world's 250 largest companies have issued CSR reports in 2008 [4].

Semi-TDPD is a portion of "Third degree price discrimination". Let $\mathrm{p}$ be the price of a product. Then, only the customer whose reservation price is higher than $\mathrm{p}$ buys it. However, to increase the revenue the product can be sold to some customers at a lower price, according to their "willing to pay". Adopting this type of a price discrimination strategy is an important tool in competition. This strategy is also called "Third degree price discrimination". It is assumed that manufacturers gain a portion of "Third degree price discrimination" revenue as Semi-TDPD.

The rest of this paper organized as follows. Section 2 surveys the related literature. In Section 3, we state the problem and assumptions including CSR and Semi-TDPD relations. A mathematical model is also developed to study the new revenue sharing approach. To illustrate the proposed method and the results of the model, some numerical examples are presented in Section 4. Finally, Section 5 provides the conclusions and presents some topics for future research.

\section{Survey of Literature}

There exists a rich literature on supply chain coordination specially upon collaboration and integration in SCM due to the increasing emphasis on efficient SC [5]. Arshinder et al. [6] and Hezarkhani et al. [7] presented several strategies on SCM coordination to enrich the SCM performances such as setting contract, utilizing information technology, information sharing and joint decision making. In the contract setting strategy, popular contracts are franchising operation, twopart tariff [8], price or quantity discounting [9], [10], [11], as well as revenue (profit) sharing [12], [13], [14]. See also the review papers on supply chain coordination with various perspectives that have been prepared by Taylor [15], Cachon [16] and Hezarkhani and Kubiak [7].

Revenue sharing contract is one of the most popular coordination approaches. Wang [13], Chen et al. [17] and Giannoccaro and Pontrandolfo [18] investigated the case of revenue sharing contract when one partner (retailer or manufacturer) gives a portion of his revenue to other partner. Hou et al. [19] implemented the revenue sharing contract on manufacturer-retail chain by considering the retailer's profit. Giannoccaro and Pontrandolfo [18] proposed a model of revenue sharing coordination on a three echelon SC. Koulamas [20] presented a new type of revenue sharing contract and compared it with a traditional ordering environment. Revenue sharing contract can be combined with other types of coordination contracts such as the one given in [21]. A revenue sharing contract on video rental industry was developed by Dana Jr. and Spier in [22].

Corporate social responsibility (CSR) is increasingly becoming a popular business concept in developed economies [2]. Fernández-Kranz et al. [24] and Kitzmueller et al. [25] illustrated stakeholders and shareholders pressurized the business goals to look the human, social and environmental issues. Ageron et al.'s study [23] showed that customers were willing to pay higher 
prices for products with CSR attributes. Burke and Logsdon [24] examined social responsibility which created strategic benefits for firms. Murphy et al. [25] mentioned that some companies accepted the concept of CSR because of the economic benefit. Ni and Li [26] presented a gametheoretic analysis of SC to obtain equilibriums for both simultaneous-move and sequential-move of CSR games. Modak [27] analyzed the coordination of a manufacturer-distributer-retailer supply chain, while the manufacturer utilized corporate social responsibility (CSR). Panda [4] also applied a revenue sharing contract on manufacturer-retailer chain by considering CSR of manufacturer and retailer.

A large body of literature on the study of price discrimination shows the importance of this matter. A macroeconomic model of international price discrimination for a two-country model was illustrated by Corsetti and Dedola [28]. Stole [29] presented a survey of price discrimination theory as it applied to imperfectly competitive markets. Bergemann [30] showed customer segmentation and third degree discrimination pricing made more profit against option without these feature.

What makes this paper different from the other ones in the literature are:

- In the existence revenue sharing contract, one partner (manufacturer or retailer) pays a portion of his revenue to the other one in order to motivate him for more coordinating at the end of an agreed period, while here revenue sharing is accomplished at the sale point in each sell. After selling, retailer cashes his portion of the commodity/service price and pays the remaining price to the manufacturer. This revenue sharing contract enforces the retailer's position in sale situation by sharing the risk of discount between partners.

- New type of revenue sharing contract authorizes the retailer to bargaining with customer respect to his/her WTP (willing to pay). Semi-TDPD strategy makes it possible to exploit the opportunity of customer behavior, by adopting a price discrimination strategy. According to this strategy, some customers who cannot or are not willing to pay the posted price, are allowed to purchase at lower prices through bargaining.

- The literature has utilized CSR (Corporate sociality responsibility) in a basic model of SCM, while here it is applied in an integrated model of revenue sharing coordination mechanism with price discrimination and SCM benefits of its advantage.

\section{Problem Statement}

We consider that a manufacturer distributes his single product through a retailer channel. The manufacturer determines the wholesale price $W$ and the retailer optimizes the retailer price $p$ accordingly. The demand function is expressed as $D(p)=a_{0}-b p$, as utilized by several researchers [31-33].

Here, we coordinate the mentioned distribution system by developing a new type of revenue sharing mechanism that accomplishes at sale point by adopting CSR and Semi-TDPD concepts. Therefore, first we present centralized and decentralized systems and then a proposed revenue sharing model. To evaluate the performance of the proposed revenue sharing model, these three scenarios are compared. 


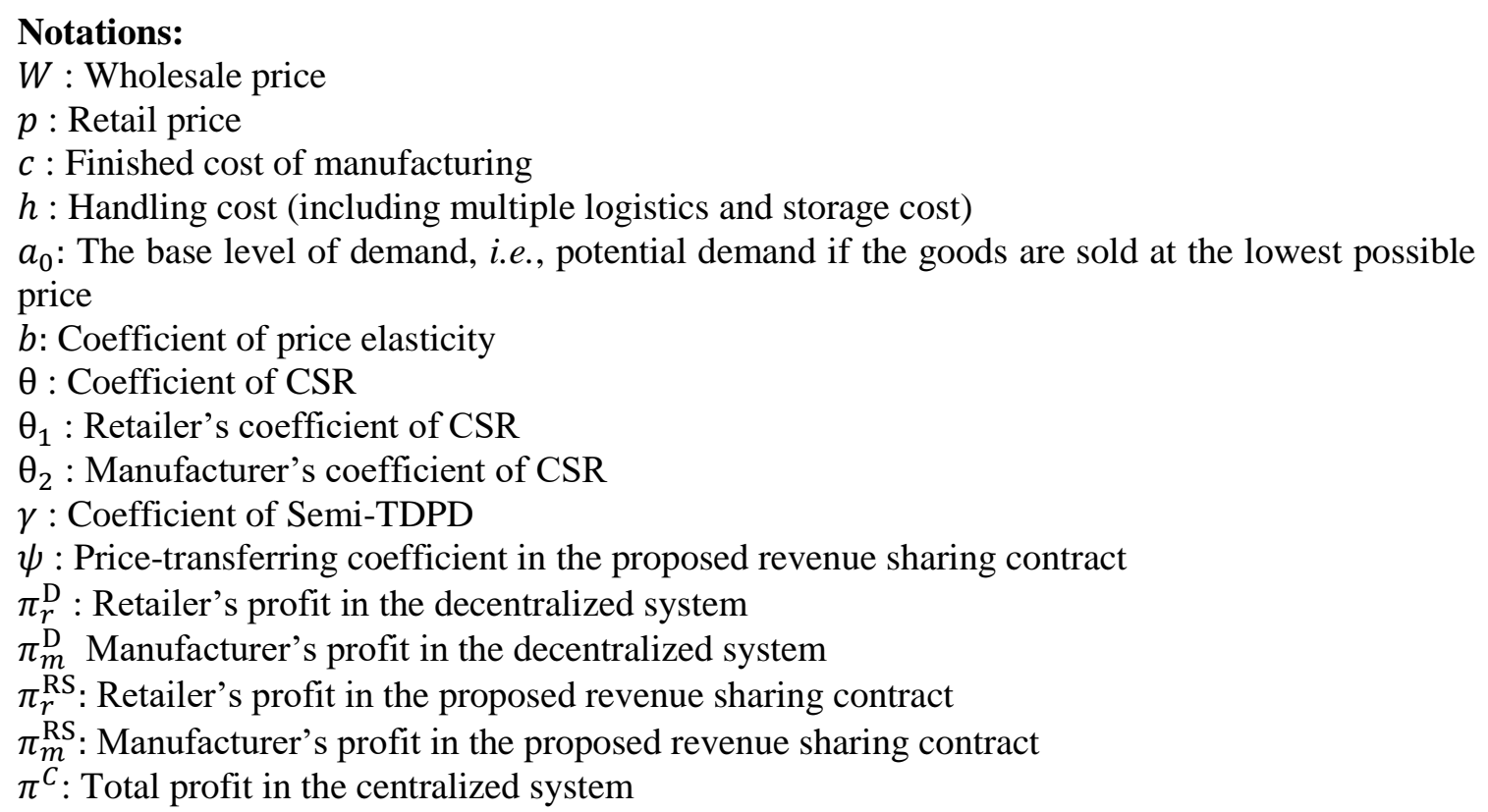

CSR (Corporate Sociality Responsible): CSR is modeled by utilizing a consumer surplus concept $[4,27,34]$. To determine the consumer surplus, it is necessary to use the concept of "reservation price", which is the highest price a customer is willing to pay for the product. It is also called "willing to pay" of customers. In other words, if the posted price of a product is $p$, then only the customers whose reservation price is higher than $p$ buy the product. The difference between the "reservation price" of a customer and the posted retail price, $p$, is called the surplus of the customer. Thus, the total customer surplus is

$$
\text { Costumer Surplus }=\int_{\frac{a_{0}-p}{b}}^{\frac{a_{0}}{b}}\left(a_{0}-b y\right) d y=\int_{p}^{P_{\text {Max }}} b(x-p) d x,
$$

where $P_{\text {Max }}=\frac{a_{0}}{b}$. CSR can be a fraction of customer surplus, depending on each firm's policy, as follows:

$$
\text { Costumer Surplus }=\int_{\frac{a_{0}-p}{b}}^{\frac{a_{0}}{b}}\left(a_{0}-b y\right) d y=\int_{p}^{P_{M a x}} b(x-p) d x,
$$

where $\theta \in[0,1]$ is called the "coefficient of CSR". If $\theta=1$, then it implies that the manufacturer maximizes the welfare of his stakeholders, while $\theta=0$ results in the optimization of the manufacturer's pure profit.

Semi-TDPD (Semi Third Degree Price Discrimination): If Semi-TDPD is applied, then the manufacturer can consider a discount for the customers whose reservation price is less the posted price in order to enhance the income. A product can be sold based on these customer's "willing to pay" as long as the price is within an acceptable range, i.e., $p \in[c, p]$. The contribution of the SemiTDPD on total revenue is 


$$
\int_{c}^{p} b(x-c) d x
$$

since it is supposed that the manufacturer gains a partial of this revenue. The obtained revenue of Semi-TDPD strategy is $\gamma \int_{P_{\text {Min }}}^{p} b(x-c) d x$, where $\gamma \in[0,1]$ is called the "coefficient of SemiTDPD”.

\section{Models}

To investigate the impact of the proposed revenue sharing on a decentralized distribution system, three scenarios are presented and compared.

\subsection{Centralized System}

Since efficiency is achieved when a distribution system is operated centrally, we propose it here in order to evaluate our proposed revenue sharing contract model with CSR and Semi-TDPD practices. The profit function of the channel is

$$
\pi^{C}=(p-c) \int_{p}^{P_{M a x}} b d x+\gamma \int_{P_{\text {Min }}=C}^{p} b(x-c) d x+\theta \int_{p}^{P_{M a x}} b(x-p) d x
$$

Since $\frac{\partial \pi^{C}}{\partial p}=0$ and $\frac{\partial^{2} \pi^{C}}{\partial p^{2}}<0$, the optimal price is achieved as

$$
p=\frac{P_{\operatorname{Max}}(1-\theta)+c(1-\gamma)}{2-\gamma-\theta}
$$

\subsection{Decentralized System with no Coordination}

It is presumed that manufacturer and retailer adopt the CSR strategy with $\theta_{1}$ and $\theta_{2}$ as CSR's coefficient, respectively. Therefore, the total profit for them are achieved as follows:

$$
\begin{aligned}
& \pi_{r}^{\mathrm{D}}=(p-W) \int_{p}^{P_{\text {Max }}} b d x+\gamma \int_{P_{\text {Min }}=W}^{p} b(x-W) d x+\theta_{1} \int_{p}^{P_{\text {Max }}} b(x-p) d x, \\
& \pi_{m}^{\mathrm{D}}=(W-c) \int_{p}^{P_{\text {Max }}} b d x+\gamma \int_{P_{\text {Min }}=W}^{p} b(W-c) d x+\theta_{2} \int_{p}^{P_{\text {Max }}} b(x-p) d x,
\end{aligned}
$$


where $\pi_{r}^{\mathrm{D}}$ and $\pi_{m}^{\mathrm{D}}$ are the profit of retailer and manufacturer, respectively and $P_{\text {Min }}=W$ and $P_{\text {Max }}=$ $\frac{a_{0}}{b}$. In both (2) and (3) the first term represents the pure profit, while the second and third terms represent the contribution of CSR and Semi-TDPD, respectively.

Proposition 1. The optimal retail and wholesale prices are

$$
p=\frac{P_{\operatorname{Max}}\left(1-\theta_{1}\right)+W(1-\gamma)}{2-\gamma-\theta_{1}}
$$

and

$$
\begin{aligned}
& W=\frac{1}{2}\left(1+\frac{\theta_{2}}{\theta_{2}+4-2 \gamma-2 \theta_{1}}\right) P_{\text {Max }}+\frac{c\left(2-\gamma-\theta_{1}\right)}{\theta_{2}+4-2 \gamma-2 \theta_{1}} \\
& -\frac{\gamma\left(P_{\text {Max }}-P_{\text {Min }}\right)\left(2-\gamma-\theta_{1}\right)^{2}}{(\gamma-1)^{2}\left(\theta_{2}+4-2 \gamma-2 \theta_{1}\right)} .
\end{aligned}
$$

Proof. In this contract, the decision-making mechanism of manufacturer and retailer is formulated through a Stackelberg game model. The manufacturer as leader sets the wholesale price $(\omega)$ to optimize his profit. Then, the retailer as follower determines the retail price to maximize his profit. Equations (4) and (5) can be rewritten as follows:

$$
\begin{aligned}
& \pi_{r}^{\mathrm{D}}=b\left(\gamma\left(\frac{p^{2}}{2}-W p\right)+\gamma\left(\frac{W^{2}}{2}\right)+(p-W) P_{\text {Max }}-(p-W) p+\theta_{1}\left(\frac{P_{\text {Max }}^{2}}{2}-p P_{\text {Max }}\right)-\theta_{1}\left(\frac{p^{2}}{2}\right)\right) \\
& \pi_{m}^{\mathrm{D}}=b\left((\gamma-1)(W-c) p-\gamma(W-c) W+(W-c) P_{\text {Max }}+\theta_{2}\left(\frac{P_{\text {Max }}{ }^{2}}{2}-p P_{\text {Max }}\right)-\theta_{2}\left(\frac{p^{2}}{2}-p^{2}\right)\right) .
\end{aligned}
$$

The retailer profit function (4) is concave with respect to retailer price, since $\frac{\partial^{2} \pi_{r}^{D}}{\partial p^{2}}<0$. Then, the optimal retail price $p$ is determined by setting $\frac{\partial \pi_{r}^{\mathrm{D}}}{\partial p}$ equal to zero. By substituting $p$ in (5) and also setting $\frac{\partial \pi_{m}^{\mathrm{D}}}{\partial W}$ equal to zero, the wholesale price $(w)$ is obtained.

Proposition 2. The manufacturer and retailer profit functions are increasing function of both CSR and Semi-TDPD coefficients. Moreover, product price is an increasing function of the Semi-TDPD coefficient but a decreasing function of the CSR coefficient

Proof. The following equations provide the proof:

$$
\begin{aligned}
& -\frac{\partial \pi_{r}^{\mathrm{D}}}{\partial \theta_{1}} \geq 0, \frac{\partial \pi_{m}^{\mathrm{D}}}{\partial \theta_{1}} \geq 0, \frac{\partial \pi_{r}^{\mathrm{D}}}{\partial \gamma} \geq 0 \text { and } \frac{\partial \pi_{m}^{\mathrm{D}}}{\partial \gamma} \geq 0, \\
& -\frac{\partial p}{\partial \theta_{1}} \leq 0, \frac{\partial p}{\partial \gamma} \geq 0 .
\end{aligned}
$$




\subsection{Proposed Revenue Sharing Contract}

In this section, an enhanced revenue sharing contract is presented which is more practical as compared to other revenue sharing contracts. In this contract the retailer sets the retail price $(p)$ and the manufacturer adjusts the wholesale price accordingly. Following this approach, the retailer gives a specified percentage of the retail price $(\psi p)$ to the manufacturer for each sale. This feature empowers the retailer to set the price based on the market situation and customer's WTP (willing to pay), where $\psi$ is called the price-transferring coefficient.

According to this contract, the act of revenue sharing is done at each sale. Therefore, it does not need a lot of efforts and accounting transactions to share. Since the retailer has authority on the third discriminate price, he can give a discount to some customers whose reservation price is less than the posted price of $(p)$. In this contract, the profit functions of manufacturer and retailer are

$$
\begin{aligned}
& \pi_{r}^{\mathrm{RS}}=(p-\psi p) \int_{p}^{P_{\text {Max }}} b d x+\int_{\frac{c}{\psi}}^{p} b(x-\psi x) d x+\theta_{1} \int_{p}^{P_{\text {Max }}} b(x-p) d x \\
& \pi_{m}^{\mathrm{RS}}=(\psi p-c) \int_{p}^{P_{\text {Max }}} b d x+\int_{\frac{c}{\psi}}^{p} b(\psi x-c) d x+\theta_{2} \int_{p}^{P_{\text {Max }}} b(x-p) d x,
\end{aligned}
$$

where $P_{\text {Min }}=\frac{c}{\psi}$ and $P_{\text {Max }}=\frac{a_{0}}{b}$.

Proposition 3. If the price-transferring coefficient $(\psi)$ is selected within the specified range of $\psi \in$ $\left[\psi_{3} ; \psi_{4}\right]$, then the retail price is also within an acceptable range, i.e., $P_{\min }=\frac{c}{\psi} \leq p \leq P_{\max }$, where

$$
\begin{aligned}
& \psi_{3}=\frac{\left(c(\gamma-2)-\left(1-\theta_{1}\right) P_{\text {Max }}\right)-\left(\left(\left(1-\theta_{1}\right) P_{\max }-c(\gamma-2)\right)^{2}-4 c\left(2-\gamma-\theta_{1}\right) P_{\max }\right)^{0.5}}{2 P_{\max }}, \\
& \psi_{4}=\frac{\left(c(\gamma-2)-\left(1-\theta_{1}\right) P_{\text {Max }}\right)+\left(\left(\left(1-\theta_{1}\right) P_{\max }-c(\gamma-2)\right)^{2}-4 c\left(2-\gamma-\theta_{1}\right) P_{\max }\right)^{0.5}}{2 P_{\max }} .
\end{aligned}
$$

Proof. From (8):

$$
\begin{gathered}
\pi_{r}^{\mathrm{RS}}=b\left(\gamma(1-\psi)\left(\frac{p^{2}}{2}\right)-\frac{\gamma(1-\psi)}{2}\left(\frac{c}{\psi}\right)^{2}+p(1-\psi) P_{\text {Max }}-p^{2}(1-\psi)\right. \\
\left.+\theta_{1}\left(\frac{P_{\text {Max }}{ }^{2}}{2}-p P_{\text {Max }}\right)+\theta_{1} \frac{p^{2}}{2}\right)
\end{gathered}
$$

Since $\pi_{r}^{\mathrm{RS}}$ is a concave function with respect to $p$, then the optimal price $p^{*}$ is derived from $\frac{\partial \pi_{r}^{\mathrm{RS}}}{\partial p}=0$ :

$$
p^{*}=-\frac{\left(1-\psi-\theta_{1}\right)}{\left((\gamma-2)(1-\psi)+\theta_{1}\right)} P_{M a x} .
$$


It is shown that $p^{*} \leq P_{\max }$, if the following relation which is extracted from (10) holds:

$$
0 \leq \frac{(\gamma-1)(1-\psi)}{\left(-\psi(\gamma-2)+(\gamma-2)+\theta_{1}\right)}
$$

Since $-\psi(\gamma-2)+(\gamma-2)+\theta_{1} \geq 0$, if $0 \leq \psi \leq \psi_{1}=\frac{(\gamma-2)+\theta_{1}}{(\gamma-2)}=1+\frac{\theta_{1}}{(\gamma-2)}$ and $(\gamma-1)(1-$ $\psi) \geq 0$ if $0 \leq \psi \leq \psi_{2}=1$, then $p \leq P_{\max }$, if $\psi \epsilon\left[0 ; \psi_{1}\right]$.

* It is shown that $P_{\min }=\frac{c}{\psi} \leq p^{*}$, if the following relation holds:

$$
0 \leq \frac{P_{M a x} \psi^{2}+\left(c(\gamma-2)-\left(1-\theta_{1}\right) P_{M a x}\right) \psi+c\left(2-\gamma-\theta_{1}\right)}{\left(-\psi(\gamma-2)+\gamma-2+\theta_{1}\right) \psi} .
$$

Numerator of (11) has two roots, called $\psi_{3}$ and $\psi_{4}$, as follows:

$$
\begin{aligned}
& \psi_{3}=\frac{\left(c(\gamma-2)-\left(1-\theta_{1}\right) P_{\text {Max }}\right)-\left(\left(\left(1-\theta_{1}\right) P_{\max }-c(\gamma-2)\right)^{2}-4 c\left(2-\gamma-\theta_{1}\right) P_{\max }\right)^{0.5}}{2 P_{\max }}, \\
& \psi_{4}=\frac{\left(c(\gamma-2)-\left(1-\theta_{1}\right) P_{\text {Max }}\right)+\left(\left(\left(1-\theta_{1}\right) P_{\max }-c(\gamma-2)\right)^{2}-4 c\left(2-\gamma-\theta_{1}\right) P_{\max }\right)^{0.5}}{2 P_{\max }} .
\end{aligned}
$$

Also, $\psi_{1}$ and $\psi_{5}$ are roots of the denominator of (11)

$$
\psi_{1}=\frac{(\gamma-2)+\theta_{1}}{(\gamma-2)}=1+\frac{\theta_{1}}{(\gamma-2)} \text { and } \psi_{5}=0
$$

Using the property of second order equations, $\psi_{3} * \psi_{4}=\frac{c\left(2-\gamma-\theta_{1}\right)}{P_{\operatorname{Max}}}>0$ and $\psi_{3}+\psi_{4}=$ $-\frac{c(\gamma-2)-\left(1-\theta_{1}\right) P_{\operatorname{Max}}}{P_{\operatorname{Max}}}=1-\theta_{1}-\frac{c(\gamma-2)}{P_{\operatorname{Max}}}$. Since $\psi_{3} * \psi_{4}>0$, we have $0<\psi_{3}<\psi_{4}$. Also, $\psi_{3}+$ $\psi_{4} \leq \psi_{1}$ and $0<\psi_{3}<\psi_{4}<\psi_{1}$.

The numerator of (11) is negative, if $\psi \epsilon\left[\psi_{3}, \psi_{4}\right]$ and the denominator of (11) is negative, if $\psi \epsilon\left[\psi_{5}=\right.$ $\left.0, \psi_{1}\right]$. Therefore, (11) holds, if $\psi_{3} \leq \psi \leq \psi_{4}$.

Proposition 4. Let $\psi \in\left\{\bar{A} \cap\left[\psi_{3} ; \psi_{4}\right]\right\}$, where $\bar{A}$ is the set of all price-transferring coefficients $\psi$, which can satisfy the following relation. Then, both the retailer and the manufacturer gain more, by adopting our proposed revenue sharing in comparison with not adopting it:

$$
\begin{aligned}
& P_{\operatorname{Max}}^{2}\left(\frac{\gamma}{2}-1\right) \psi^{2}\left(1-\psi-\theta_{1}\right)^{2}+P_{\operatorname{Max}}^{2} \frac{\theta_{2}}{2} \psi\left(1-\psi-\theta_{1}\right)^{2} \\
& +P_{\operatorname{Max}} G_{2} \psi\left((\gamma-2)(1-\psi)+\theta_{1}\right)\left(1-\psi-\theta_{1}\right) \\
& +G_{1}\left((\gamma-2)(1-\psi)+\theta_{1}\right)^{2}+G_{0}\left((\gamma-2)(1-\psi)+\theta_{1}\right)^{2} \psi \geq 0 .
\end{aligned}
$$

\section{Proof.}

Retailer prefer this contract, if $\pi_{r}^{D *} \leq \pi_{r}^{R S}$. 
If $\psi p \leq W$, then the retailer gains more profit in the proposed revenue sharing contract as opposed to the decentralized model, if $\pi_{r}^{D} \leq \pi_{r}^{R S}$. By proposition 3,

$$
\begin{gathered}
\psi \frac{-\left(1-\psi-\theta_{1}\right)}{\left((\gamma-2)(1-\psi)+\theta_{1}\right)} \leq W \\
0 \leq \frac{-\psi^{2}+\psi\left(1-\theta_{1}+W(2-\gamma)\right)+W\left(\gamma-2+\theta_{1}\right)}{\left((\gamma-2)(1-\psi)+\theta_{1}\right)} .
\end{gathered}
$$

Let $\psi_{6}$ and $\psi_{7}$ be the roots of the numerator, $\frac{W\left(\gamma-2+\theta_{1}\right)}{-1}>0$ that results in $\psi_{6} * \psi_{7}>0$, and $\frac{\psi\left(1-\theta_{1}+W(2-\gamma)\right)}{-1}<0$ gives $\psi_{6}+\psi_{7}<0$. Therefore, it is concluded that $\psi_{6} \leq 0$ and $\psi_{7} \leq 0$. Moreover, the root of the denominator is $\psi_{1}=1+\frac{\theta_{1}}{(\gamma-2)}$. Based on $\psi_{6} \leq 0, \psi_{7} \leq 0$ and $\psi_{1} \geq 0$, it is obvious that $0 \leq \psi \leq \psi_{1}$ satisfies $\psi p \leq W$. From Proposition 3, $0<\psi_{3}<\psi_{4}<\psi_{1}$, and also if $\psi \epsilon\left[\psi_{3}, \psi_{4}\right]$, then an optimal price stands in an acceptable range and the retailer prefers the proposed model to the decentralized model.

Manufacturer prefers the proposed model, if $\pi_{m}^{\mathrm{RS}} \geq \pi_{m}^{\mathrm{D} *}$ :

From (9):

$$
\pi_{m}^{\mathrm{RS}}=\mathrm{b}\left(p^{2}\left(\psi\left(\frac{\gamma}{2}-1\right)+\frac{\theta_{2}}{2}\right)+p\left(-\theta_{2} P_{\text {Max }}+\mathrm{c}\right)+\psi P_{\text {Max }}^{2}-\frac{\gamma}{\psi}\left(-\frac{c^{2}}{2}\right)-\mathrm{c} P_{\text {Max }}+\theta_{2}\left(\frac{P_{\text {Max }}{ }^{2}}{2}\right)\right) .
$$

After abstracting, $\pi_{m}^{\mathrm{RS}} \geq \pi_{m}^{\mathrm{D} *}$

$$
p^{2} \psi^{2}\left(\frac{\gamma}{2}-1\right)+p^{2} \psi \frac{\theta_{2}}{2}+p \psi G_{2}+\psi^{2} G_{1}+\psi \mathrm{G}_{0}+G_{3}>0,
$$

where

$$
G_{0}=-\mathrm{c} P_{M a x}+\theta_{2}\left(\frac{P_{\text {Max }}{ }^{2}}{2}\right)-\frac{\pi_{m}^{\mathrm{D} *}}{b}, G_{1}=P_{\text {Max }}^{2}, G_{2}=-\theta_{2} P_{M a x}+\mathrm{c}, G_{3}=\frac{1}{2} \gamma \mathrm{c}^{2} .
$$

By substituting the optimal price from (10):

$$
\begin{aligned}
P_{\text {Max }}^{2}\left(\frac{\gamma}{2}-1\right) \psi^{2} & \left(1-\psi-\theta_{1}\right)^{2}+P_{\text {Max }}^{2} \frac{\theta_{2}}{2} \psi\left(1-\psi-\theta_{1}\right)^{2} \\
& +P_{\text {Max }} G_{2} \psi\left((\gamma-2)(1-\psi)+\theta_{1}\right)\left(1-\psi-\theta_{1}\right)+G_{1}\left((\gamma-2)(1-\psi)+\theta_{1}\right)^{2} \\
& +G_{0}\left((\gamma-2)(1-\psi)+\theta_{1}\right)^{2} \psi \geq 0 .
\end{aligned}
$$

If $\psi \in \bar{A}$, then the manufacturer prefers the proposed model versus decentralized model since $\pi_{m}^{\mathrm{RS}} \geq \pi_{m}^{\mathrm{D} *}$.

Therefore, $\psi \in\left[\psi_{3} ; \psi_{4}\right]$ and $\psi \in \bar{A}$ result in $\pi_{r}^{D} \leq \pi_{r}^{R S}$ and $\pi_{m}^{\mathrm{RS}} \geq \pi_{m}^{\mathrm{D} *}$, i.e., the proposed revenue sharing is preferred by the two partners of the distribution system. 


\section{Numerical Example}

In this section, we present a numerical example to illustrate the theoretical results and compare the different scenarios, Centralized System (CS), Decentralized System (DS) and the proposed Revenue Sharing (ARS). The data for this numerical example is presented in Table 1.

Table 1. Data for numerical example.

\begin{tabular}{|c|c|c|c|}
\hline$\alpha_{0}=30000$ & $b=10$ & $C=30$ & $\gamma=0.4$ \\
$\theta=0.6$ & $\theta_{1}=0.3$ & $\theta_{2}=0.3$ & \\
\hline
\end{tabular}

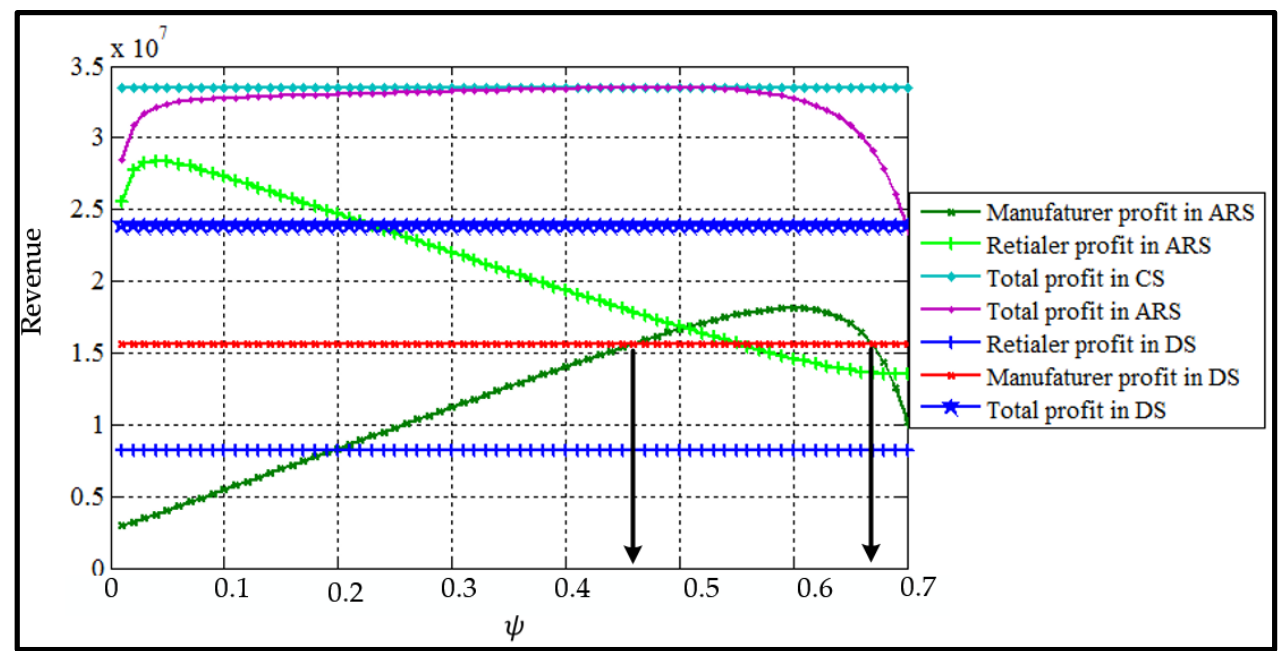

Figure 1. Impact of $\psi$ on profit function in different scenarios

In Fig. 1, the profit of different scenarios of Centralized System (CS), Decentralized System (DS) and Revenue Sharing (ARS) with respect to price-transferring coefficients in revenue sharing $(\psi)$ is illustrated. As expected, the centralized model is dominant over the other scenarios and the total profit of revenue sharing dominates the decentralized system. The profit of retailer in revenue sharing model is also higher than the profit in the decentralized system. However, the profit of the manufacturer in the revenue sharing model is higher than the profit in the decentralized system, if $\psi \epsilon[0.4701,0.679]$, since form Proposition 3 each $\psi$ is acceptable, if $\psi \epsilon\left\{\left(\psi_{3}, \psi_{4}\right)\right\}=[0.0186,0.6974]$ and from Proposition 4, with $\bar{A}=\{[0.4701,0.679] \&[0.9856,1]\}, \psi \in\left\{\bar{A} \cap\left[\psi_{3} ; \psi_{4}\right]\right\}=[0.4701,0.679]$.

Fig. 2-(a) shows that by increasing price-transferring coefficients in revenue sharing $(\psi)$, the optimal price decreases and it is lower than the one in the decentralized system.

In Fig. 2-(b) and Fig. 3, we perform sensitivity analysis on the Semi-TDPD coefficient $(\gamma)$ within the range of $[0.00-1.00]$ and with $\psi=0.65$. 
(a)

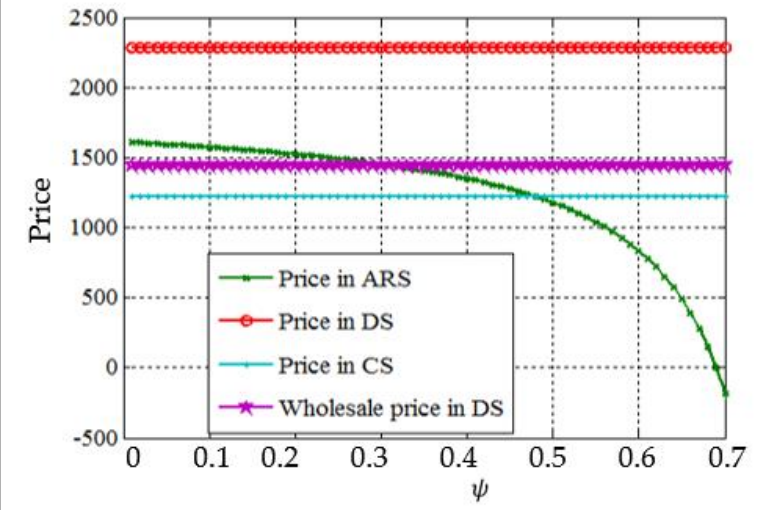

(b)

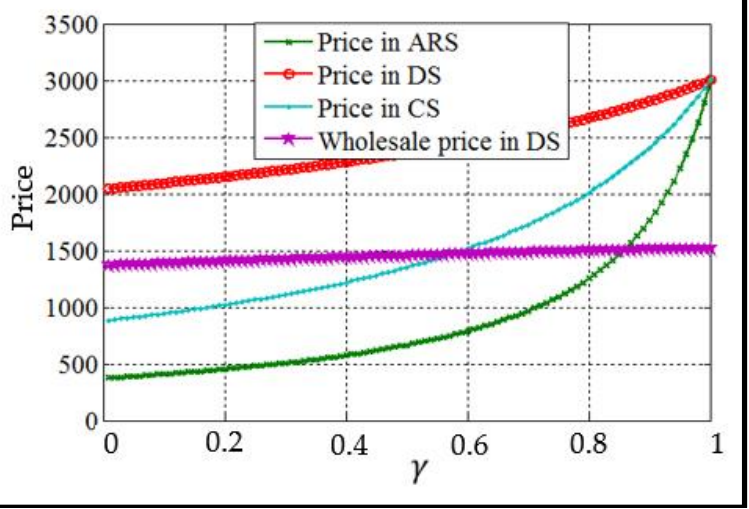

Figure 2. Impact of $\psi$ and $\gamma$ on price in different scenarios

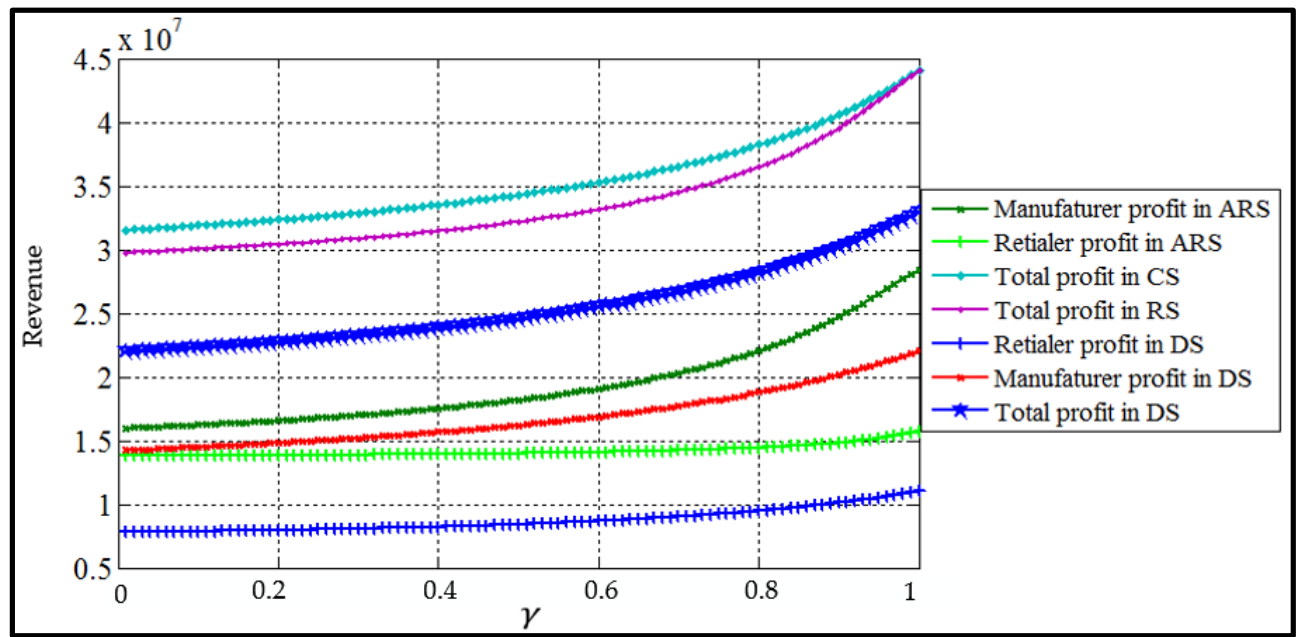

Figure 3. Impact of $\gamma$ on profits in different scenarios

\section{Conclusion}

We studied the coordination of manufacturer-retailer chain considering CSR (Corporate Sociality Responsible) and Semi-TDPD (Semi Third Degree Price Discrimination) by developing a new revenue sharing contract. This contract was based on the retail price. We determined the optimal price and profit functions of both the manufacturer and the retailer for different scenarios. The good performance of the new revenue sharing contract was shown if the optimal range of sharing was considered.

This research had a number of managerial implications in areas, where the manufacturer or retailer can provide different prices for different customers, to enhance the total revenue. This enhanced revenue sharing contract gives this feature to the retailer in order to exploit different prices for different customers.

Our work can be extended in several ways. First, it can be extended by adding new channels, such as network marketing or internet channel. Second, a new class of problems can be considered using 
a stochastic demand. Finally, the concepts of coordination mechanism can be applied to the model and the results can be compared.

\section{References}

[1] Panda, S., Modak, N. M., Basu, M. and Goyal, S. K. (2015), Channel coordination and profit distribution in a social responsible three-layer supply chain, International Journal of Production Economics, 168, 224-233.

[2] Amaeshi, K. M., Osuji, O. K. and Nnodim, P. (2008), Corporate social responsibility in supply chains of global brands: a boundaryless responsibility? clarifications, exceptions and implications, Journal of Business Ethics, 81(1), 223-234.

[3] Pedersen, E. R. and Andersen, M. (2006), Safeguarding corporate social responsibility (CSR) in global supply chains: how codes of conduct are managed in buyer-supplier relationships, Journal of Public Affairs, 6(3-4), 228-240.

[4] Panda, S. (2014), Coordination of a socially responsible supply chain using revenue sharing contract, Transportation Research, Part E: Logistics and Transportation Review, 67, 92104.

[5] Chen, J., Zhang, H. and Sun, Y. (2012), Implementing coordination contracts in a manufacturer Stackelberg dual-channel supply chain, Omega, 40(5), 571-583.

[6] Arshinder, K., Kanda, A. and Deshmukh, S. G. (2011), Supply Chain Coordination under Uncertainty,In T.-M. Choi \& T. C. E. Cheng (Eds.), Supply Chain Coordination under Uncertainty (pp. 39-82), Berlin, Heidelberg: Springer Berlin Heidelberg.

[7] Hezarkhani, B. and Kubiak, W. (2010), Coordinating contracts in SCM: a review of methods and literature, Decision Making in Manufacturing and Services, 4, 5-28.

[8] Raju, J. and Zhang, Z. J. (2005), Channel coordination in the presence of a dominant retailer, Marketing Science, 24(2), 254-262.

[9] Wang, Q. and Wang, R. (2005), Quantity discount pricing policies for heterogeneous retailers with price sensitive demand, Naval Research Logistics, 52(7), 645-658.

[10] Burnetas, A., Gilbert, S. M. and Smith, C. E. (2007), Quantity discounts in single-period supply contracts with asymmetric demand information, IIE Transactions, 39(5), 465-479.

[11] Dolan, R. J.,(1987), Quantity discounts: managerial issues and research opportunities, Marketing Science, 6(1), 1-22.

[12] Cachon, G. P. and Lariviere, M. a. (2005), Supply chain coordination with revenue-sharing contracts: strengths and limitations, Management Science, 51(1), 30-44.

[13] Wang, G., AI Xing-zheng and Deng Huaping (2009), Study on dual-channel revenue sharing coordination mechanisms based on the free riding, In 6th International Conference on Service Systems and Service Management, IEEE, China, 532-535.

[14] Yan, R. (2008), Profit sharing and firm performance in the manufacturer-retailer dualchannel supply chain, Electronic Commerce Research, 8(3), 155-172.

[15] Taylor, T. A. (2002), Supply chain coordination under channel rebates with sales effort effects, Management Science, 48(8), 992-1007.

[16] Cachon, G. P. (2001), Supply chain coordination with contracts, Handbooks in Operations Research and Management Science, (September), 227-339.

[17] Chen, J.-M., Cheng, H.-L. and Lin, I.-C. (2011), On channel coordination under pricedependent revenue-sharing: can eBay's fee structure coordinate the channel?, Journal of the Operational Research Society, 62(11), 1992-2001.

[18] Giannoccaro, I. and Pontrandolfo, P. (2004), Supply chain coordination by revenue sharing contracts, International Journal of Production Economics, 89(2), 131-139. 
[19] Hou, J., Zeng, A. Z. and Zhao, L. (2009), Achieving better coordination through revenue sharing and bargaining in a two-stage supply chain, Computers and Industrial Engineering, 57(1), 383-394.

[20] Koulamas, C. (2006), A newsvendor problem with revenue sharing and channel coordination, Decision Sciences, 37(1), 91-100.

[21] Jeuland, A. P. and Shugan, S. M. (1983), Managing channel profits, Marketing Science, 2(3), 239-272.

[22] Dana Jr., J. D. and Spier, K. E. (2003), Revenue sharing and vertical control in the video rental industry, The Journal of Industrial Economics, 49(3), 223-245.

[23] Ageron, B., Gunasekaran, A., and Spalanzani, A. (2012), Sustainable supply management: an empirical study, International Journal of Production Economics, 140(1), 168-182.

[24] Burke, L., and Logsdon, J. M. (1996), How corporate social responsibility pays off, Long Range Planning, 29(4), 495-502.

[25] Murphy, P. R., and Poist, R. F. (2002), Socially responsible logistics: an exploratory study, Transportation Journal, 41(4), 23-35.

[26] Ni, D., and Li, K. W. (2012), A game-theoretic analysis of social responsibility conduct in two-echelon supply chains, International Journal of Production Economics, 138(2), 303313.

[27] Modak, N. M., Panda, S., and Sana, S. S. (2016), Three-echelon supply chain coordination considering duopolistic retailers with perfect quality products, International Journal of Production Economics, 182(October 2016), 564-578.

[28] Corsetti, G., and Dedola, L. (2005), A macroeconomic model of international price discrimination, Journal of International Economics, 67(1), 129-155.

[29] Stole, L. A. (2007), Chapter 34 Price Discrimination and Competition, 2221-2299.

[30] Bergemann, D., Brooks, B., and Morris, S. (2015), The Limits of Price Discrimination, American Economic Review, 105(3), 921-957.

[31] Dan, B., Xu, G., and Liu, C. (2012), Pricing policies in a dual-channel supply chain with retail services, International Journal of Production Economics, 139(1), 312-320.

[32] Yue, X., and Liu, J. j. (2006), Demand forecast sharing in a dual-channel supply chain, European Journal of Operational Research, 174(1), 646-667.

[33] Huang, W., and Swaminathan, J. M. (2009), Introduction of a second channel: Implications for pricing and profits, European Journal of Operational Research, 194(1), 258-279.

[34] Modak, N. M., Panda, S., and Sana, S. S. (2016), Three-echelon supply chain coordination considering duopolistic retailers with perfect quality products, International Journal of Production Economics, 182(October 2016), 564-578. 